\title{
A violência na escola particular na rede de Minas Gerais - Brasil: desafios à formação de professores ${ }^{1}$
}

\author{
Sandra Pereira Tosta*
}

\begin{abstract}
Resumo
A pesquisa que fundamenta este artigo é inédita por tratar da violência em meio escolar, ouvindo professores de todas as modalidades de educação em escolas particulares do Estado de Minas Gerais. Assim, este artigo apresenta e discute alguns resultados da investigação, "Rede particular de ensino: vida de professor e violência na escola", realizada em parceria da PUC Minas com o Sindicato dos Professores da Rede Particular de Minas Gerais - Sinpro Minas. A investigação de natureza exploratória foi desenvolvida em duas etapas, realizando-se na primeira o georreferenciamento das escolas e dos docentes, no nível municipal, da rede particular de ensino de Minas Gerais, tendo como fonte a base de dados do Sinpro Minas, com aproximadamente 25 mil professores sindicalizados. A partir dessa base, foi identificado o número de docentes vinculados à educação básica e superior, por município em Minas Gerais; essa população foi georreferenciada por faixa etária, sexo, formação e modalidade de ensino em que atua. Na segunda etapa, foi aplicado, junto a uma amostra representativa dessa população um questionário sobre as percepções dos professores acerca dos indicadores altos de violência escolar. Os resultados indicam a existência de violência na rede privada de ensino e contribuem para a criação de estratégias de mobilização de pesquisadores, educadores e agentes socioeducativos, além do Estado, no esforço de criar políticas para prevenção e combate à violência em meio escolar. E oferece elementos teóricos e metodológicos fundamentais para se pensar a formação e a prática docente na sociedade contemporânea.
\end{abstract}

Palavras- Chave: Violência. Escola. Rede privada de Minas Gerais-Brasil. Pesquisa.

\section{Introdução}

violência no meio escolar tem mobilizado pesquisadores, agentes
socioeducativos e educadores, além do Estado, no esforço de
criar políticas para sua prevenção e seu combate. Caracterizada historicamente como um fenômeno cujas razões eram quase sempre atribuídas à população inserida em condições de desvantagem social, tais argumentos, hoje, se mostram insuficientes para dar conta da violência, tal como ela se apresenta: multifacetada, disseminada pela sociedade como um todo e em escala mundial. De fato, estamos diante de um fenômeno globalizado que atinge a todas as classes sociais, rompendo com distinções abruptas como aquelas categorias de violência centradas nos cortes de classe e de origem sociais.

Nesse quadro de radical complexidade, que gera perplexidade por vezes paralisante, uma indagação coloca-se como ponto de partida para falarmos de violência no interior da escola, especificamente, da escola particular. Seria ela em principio, violenta, como propôs Foucault, ao elencá-la no conjunto daquelas instituições que o filósofo definiu
*Profa. Doutora do Programa de Pós-graduação em Educação pela PUC Minas.

${ }^{1}$ Este texto foi original mente apresentado no $8^{\circ}$ Congresso Internacional de Educación Superior "Universidad 2012", em Havana - Cuba. 
como "totais"? Sendo assim, estaríamos diante da explosão de um fenômeno que é inerente, natural à existência de instituições tais como a escolar?

De todo modo, ainda que concordemos com essa premissa, isto não diminui ou simplifica os estudos mais expressivos no nível internacional, os quais objetivam elaborar um quadro teórico que explicite o cenário da violência e que possa subsidiar políticas públicas ou privadas de intervenção para sua prevenção e combate.

Essas e outras preocupações conduziram ao estudo pioneiro que realizamos sobre as percepções de professores da rede de ensino particular de Minas Gerais, relativamente à violência em meio escolar. Considerando o quadro de pesquisas ainda muito incipientes sobre a relação violência/escola particular e violência/professor, acreditamos que nosso trabalho oferece grandes contribuições para a compreensão dessa realidade e de como o trabalho docente nela se desenvolve.

\section{Desenvolvimento}

A pesquisa "Rede Particular de Ensino: Vida de Professor e Violência na Escola" foi realizada em parceria pelo Programa de Pós-graduação em Educação, através do seu Grupo de Pesquisas e em Educação e Culturas - Educ e pelo Programa de Pósgraduação em Geografia - Tratamento da Informação Espacial por meio do seu Grupo de Pesquisa GIS - Sistemas de Informação Geográfica, da PUC Minas, e o Sindicato dos Professores da Rede Particular de Minas Gerais (Sinpro Minas), contando com uma equipe de pesquisadores e bolsistas de iniciação científica dos dois programas de pósgraduação. A investigação foi concluída em 2009 (TOSTA, 2009)².

A investigação de natureza exploratória foi desenvolvida em duas etapas, em que, na primeira se realizou o georreferenciamento das escolas e dos docentes, no nível municipal, da rede particular de ensino de Minas Gerais, tendo como fonte a base de dados do Sinpro Minas, com quase 25 mil professores sindicalizados. A partir dessa base de dados, foi identificado o número de docentes vinculados à educação básica e superior, por município em Minas Gerais; e se mapeou essa população por faixa etária, sexo, formação e modalidade de ensino em que atua.

$\mathrm{Na}$ segunda etapa, foi aplicado, junto a uma amostra representativa dessa população de professores, um questionário, obtendo-se as seguintes informações: evidências de indicadores ou fatos de violência escolar e sua frequência; descrição do tipo de violência; percepção de como o professor se vê e se sente diante da violência; levantamento de situações de envolvimento direto em atos de violência; consequências da violência escolar em sua vida; tratamento dado pela gestão escolar às situações de violência; divulgação das situações de violência pela mídia.

O questionário, resultado de debates e consultas a instrumentos similares, foi constituído de três grandes blocos de informações que contemplaram dados profissionais, formação profissional e violência. Neste último, buscou-se captar, para interpretar, a percepção construída e declarada pelo professor respondente sobre a 
violência em meio escolar e os modos de lidar o fenômeno em sua vida profissional. Assim, foram apresentadas a ele inúmeras situações para que opinasse se as considerava violentas ou não; e em caso positivo, se já havia presenciado essas situações na sua escola e quais sujeitos estavam envolvidos nessas situações: professor, aluno, direção, outros profissionais, o entorno. Quando o professor respondente esteve envolvido em situação de violência, a pesquisa quis saber a quem ele recorreu para buscar apoio e medidas de contenção da mesma. Em seguida, procurou-se saber em que tempos, turnos e espaços escolares as situações de violência ocorriam e com que frequência. Por meio de um conjunto de afirmativas para que o professor opinasse, procurou-se conhecer também sua percepção sobre fatores que poderiam motivar a violência em meio escolar; que fatores poderiam contribuir para aumentar ou diminuir, combater e prevenir a violência e se a formação acadêmica o preparou para lidar com a violência na escola. O questionário foi encerrado com pergunta aberta, em que se procurou saber a percepção do professor sobre a importância e papel da escola na sociedade atual.

\section{Universo de professores pesquisados}

\section{Tabela 1 - Calculo Amostral com correção da variância - Proporção conservadora} (50\%) Confiabilidade de 95\% - Erro precisão (ou amostral): 5\% - Margem de Perdas computadas: $10 \%$

\begin{tabular}{|c|c|c|c|c|c|c|}
\hline \multirow{2}{*}{ Regional Estadual } & \multirow{2}{*}{ Cód. Região } & \multirow{2}{*}{ Total de Profs } & \multirow[b]{2}{*}{ Peso } & \multicolumn{2}{|c|}{ Sexo } & \multirow[b]{2}{*}{ Amostra } \\
\hline & & & & feminino & masculino & \\
\hline BARBACENA & 1 & 1.540 & 0.063 & 17 & 9 & 26 \\
\hline CATAGUASES & 2 & 530 & 0.022 & 12 & 2 & 14 \\
\hline CDDADES AT, BH & 3 & 514 & 0.021 & 14 & 4 & 18 \\
\hline CORONEL FABRICIANO & 4 & 697 & 0.029 & 13 & 8 & 21 \\
\hline DIVINOPOUUS & 5 & 1.282 & 0.053 & 23 & 8 & 31 \\
\hline GOVERNADOR VALADARES & 6 & 590 & 0.024 & 10 & 8 & 18 \\
\hline GRANDE BH & 7 & 12.332 & 0.505 & 239 & 114 & 353 \\
\hline MONTES CLAROS & 8 & 1.067 & 0.044 & 25 & 12 & 37 \\
\hline POÇOS DE CALDAS & 9 & 619 & 0.025 & 19 & 3 & 22 \\
\hline PONTE NOVA & 10 & 479 & 0.020 & 12 & 3 & 15 \\
\hline POUSO ALEGRE & 11 & 790 & 0.032 & 13 & 9 & 22 \\
\hline UBERABA & 12 & 1.007 & 0.041 & 19 & 6 & 25 \\
\hline UBERLANDIA & 13 & 1.507 & 0.062 & 31 & 18 & 49 \\
\hline VARGINHA & 14 & 1.453 & 0.060 & 25 & 10 & 35 \\
\hline Total & & 24,407 & 1.00 & 472 & 214 & 685 \\
\hline
\end{tabular}

Fonte: SinproMinas/ EDUC/ GIS

\section{Resultados principais}

Os dados da pesquisa permitiram formular as seguintes constatações: no magistério das escolas da rede de ensino particular existe a predominância de professoras sobre professores. Em relação à idade, a maioria dos professores se encontrava na faixa entre 30 e 49 anos de idade, com maior concentração na faixa entre 40 e 49 anos. Quase todos possuem curso superior, muitos com especialização e mestrado, porém, não se percebe a continuidade da formação da maior parte dos entrevistados. 
Outra constatação é que a formação acadêmica, segundo a maioria, não os preparou para compreender e lidar com o fenômeno da violência na escola. Do mesmo modo, pelo menos a metade dos professores disse que a escola onde trabalhava não os preparava para lidar com a violência, embora a minoria dos entrevistados acreditasse na possibilidade de que os estudos continuados pudessem ser profícuos nessa tarefa de enfrentar a violência na instituição escolar.

A maioria expressiva dos professores trabalhava em uma só escola e somente na rede de ensino particular não confessional. Entre os que trabalhavam em mais de uma escola, quase todos davam aulas em instituições da rede pública estadual. Segundo os professores entrevistados, pelo menos metade dos seus alunos pertencia à classe $C$, correspondendo, segundo os indicadores do IBGE, ao que se conhece como classe média. Os alunos considerados por eles como sendo da classe A constituíam minoria. A carga horária de trabalho semanal dos professores variava no intervalo de até 10 a 40 horas, destacando-se uma maioria que trabalhava de 16 a 20 horas. $\mathrm{Na}$ questão em que se buscou a opinião dos professores sobre situações que poderiam ser consideradas como violência, a totalidade dos respondentes se manifestou. É importante destacar que dentre as situações confirmadas como sendo de violência, tais como as agressões verbais, as gozações e intimidações ou mesmo a indisciplina têm sido problematizadas em outras investigações, uma vez que, em muitas delas, essas situações são consideradas simplesmente como indisciplina ou incivilidades (DEBARBIEUX, 2002; AMADO, 2001; GONÇALVES e TOSTA, 2008).

De forma generalizada, os professores disseram não ter presenciado esses tipos de violência na sua escola. As exceções ficaram por conta da agressão verbal, danos ao patrimônio da escola, as lesões aos direitos e à autonomia docente, os apelidos e gozações - estas últimas correspondentes ao que se denomina bullying por inúmeros estudiosos (BLAYA, 2002). Confirmando, também, o que dizem outros estudos, a indisciplina, nessa pesquisa, foi considerado como violência. Um expressivo número de professores entrevistados apontou a direção e a coordenação como instâncias a quem recorriam quando se sentiam violentados na escola. Por outro lado, pode-se inferir que os professores reconhecem a autonomia desses dirigentes e depositam neles confiança para resolver os conflitos na instituição. Em relação aos sujeitos envolvidos nas situações de violência ocorridas nas escolas, a expressiva maioria das respostas obtidas refere-se ao par professor-aluno. Os professores confirmaram a ocorrência de situações de violência em diferentes turnos e em diferentes espaços escolares.

Tais indicadores permitem afirmar a existência de violência nas escolas da rede de ensino particular e o envolvimento do professor nas situações de violência. Confirma-se também que a sala de aula continua sendo o foco de tensão que se concentra entre professor e aluno. Nesse sentido, importa destacar que as opiniões dos professores, no conjunto, permitiram um diálogo com as categorias de violência apresentadas por diversos estudiosos da temática e referenciaram a análise 
dos resultados desta pesquisa (ARENDT, 2001; MAFESOLLI, 1987; GUIMARÃES, 1996). Constatação que indica, ainda, que, em uma investigação de natureza qualitativa, tais percepções podem ser aprofundadas para uma análise mais situada e complementar a essas.

Segundo os professores, as causas da violência na escola estão relacionadas: à omissão familiar; à presença de gangues; ao tráfico e uso de drogas; à falta de diálogo entre a escola e seu entorno; ao tratamento prepotente dispensado pelos alunos aos diversos profissionais da escola; à indiferença dos funcionários para com eles - alunos e professores; à região violenta de inserção da escola, bem como à criminalidade existente nas suas imediações e a atitudes violentas estimuladas pela mídia.

No que se refere à relação pedagógica, os professores concordaram que o despreparo acadêmico e pessoal dos docentes para lidar com o fenômeno, bem como a falta de diálogo entre estes e os alunos contribuem para a violência em meio escolar. Denunciaram, a exemplo de outras pesquisas sobre o tema, a omissão dos meios de comunicação na divulgação da realidade da escola particular, no tocante à violência. Pelo menos metade dos professores entrevistados confirmou a existência de práticas do afastamento, suspensão e/ou demissão dos envolvidos em situações de violência, incluindo o professor, adotadas pela direção para amenizar tais conflitos. Metade dos professores negou qualquer tipo de consequência advinda da violência nas suas escolas, em sua vida pessoal e profissional. Os demais que opinaram, apontaram, predominantemente, o stress como efeito dessa violência.

É animador constatar que a quase totalidade dos professores rejeitou a ideia de que a violência na escola não tenha solução, porque isso evidencia que políticas públicas adequadas à realidade da escola terão seguramente seu apoio. A exemplo de estudos anteriores sobre esse tema, mais uma vez se compreende por que os professores ainda continuam na escola e persistem em seu papel de ensinar e educar, não obstante as condições adversas de seu trabalho. Com relação ao papel da escola na atualidade, a dispersão de respostas expressa o conflito vivenciado pela instituição que tem sido constantemente requisitada para outros papéis para os quais não estápreparada. A escola, historicamente, ainda se encontra arraigada no desempenho de papéis que não respondem mais às necessidades da sociedade contemporânea.

Assim, e paradoxalmente, a pesquisa permite concluir que o papel que a maioria dos professores atribuiu à escola atualmente é o de substituta da família na educação de seus filhos. Outros ainda reconheceram o papel social da escola de ensinar valorese formar cidadãos. Uns poucos consideraram que o papel da escola é o de instruir e educar. 


\section{Conclusões}

Os resultados da pesquisa apontam claramente que a formação de professores está defasada e urge que as instituições de ensino superior busquem leituras mais abrangentes que possibilitem um entendimento o mais próximo possível da realidade de violência que afetam as escolas, seja aquela produzida em seu interior, seja aquela produzida além de seus muros, mas que se fazem valer dentro da escola. Um fenômeno que envolve diretamente todos os sujeitos da comunidade escolar, portanto, o professor está entre eles e se vê acuado e sem recursos que lhe permitam sair dos impasses criados por fatos violentos e que, independentemente de sua vontade, ele os vivencia. E tais vivências cada vez mais fazem parte de seu cotidiano.

Acreditamos, assim, que essa é uma situação que não pode deixar de ser considerada desde a discussão de políticas públicas de formação de professores até a elaboração de projetos pedagógicos nas escolas. Não se pode mais produzir estratégias de formação, como o currículo, por exemplo, fechando os olhos para essa situação, pois, ela atravessa o cotidiano escolar e o não escolar no qual o professor está inserido.

E é preciso afirmar sempre que ser professor não é simplesmente saber dar aulas ou ter didática, mesmo porque esse saber é, ao mesmo tempo, um saber ser que se reconfigura nas dinâmicas que o docente estabelece ao longo de sua trajetória pessoal e profissional, cognitiva e afetiva, material e simbólica; portanto, é um saber e saber ser e fazer articulados e em permanente construção. Ou seja, a formação docente é resultado de uma construção cotidiana, que não se limita a formação inicial; a saberes científico apenas, mas também àqueles da experiência e que resultam de inserções e escolhas que vamos fazendo ao longo de um percurso. Construções de um sujeito formado e convocado a exercer seu trabalho em conjunturas nem sempre favoráveis como essa que a pesquisa apresentou.

Finalizando, podemos reafirmar que a violência apresenta-se, hoje, em um quadro muito mais complexo; é um fenômeno global e envolve a todas as camadas da população, principalmente os jovens. Portanto, ela não é e nem pode ser interpretada como um fenômeno localizado e exclusivamente ligado às camadas pobres, de periferia; negros, analfabetos e desempregados. Tal quadro sinaliza claramente para a necessidade de se repensar modelos de formação de formadores, por um lado. Por outro, aponta para a importância de pesquisas interdisciplinares, estratégias de investigação comparadas em nível internacional, com a articulação de métodos quantitativos e qualitativos sobre violência e escola. 


\begin{abstract}
s
The research which is the base for this article is unique because of its way to treat violence at school, listening to teachers of all modalities of education in private schools of the State of Minas Gerais. Thus, this paper presents and discusses some results of the investigation, "Private schools Network: the life of a teacher and school violence", carried out in partnership with the PUC-Minas Teachers Union Network Private Minas Gerais - Minas Sinpro. The exploratory investigation was conducted in two stages, performing the first georeferencing of schools and teachers at the municipal level, the private schools of Minas Gerais, having as source the database Sinpro Minas, with approximately 25,000 unionized teachers. From this base, it was identified the number of teachers linked to basic and higher education, by municipality in Minas Gerais, this population was georeferenced by age, sex, education and type of education in which it operates. In the second stage, has been applied, along with a representative sample of this population a questionnaire on teachers' perceptions on indicators of high school violence. The results indicate the existence of violence in private schools and contribute to the creation of strategies for mobilizing researchers, educators and workers, in addition to the state in an effort to create policies to prevent and combat violence in schools. And offers theoretical and methodological elements fundamental to think training and teaching practice in contemporary society.
\end{abstract}

Keywords: Violence. School. Private network of Minas Gerais-Brazil. Research.

\title{
Referências
}

AMADO, João. Interação pedagógica e indisciplina na aula. Porto: Asas Editora, 2001.

ARENDT, Hannah .O poder e violência. Rio de Janeiro: Relume Dumará, 2001.

BLAYA, C. Clima escolar e violência nos sistemas de ensino secundário da França e da Inglaterra. In: DEBARBIEUX, E.; BLAYA, C. (Org.) Violência nas escolas e políticas públicas. Brasília: UNESCO Brasil, 2002. p. 225-247.

DEBARBIEUX, E.; BLAYA, C. (Org.) Violência nas escolas: dez abordagens européias. Brasília: UNESCO, 2002.

GUIMARÃES, Á. M. A dinâmica da violência escolar: conflito e ambigüidade. Campinas: Autores Associados: 1996.

GONÇALVES, Luiz Alberto de Oliveira; TOSTA, Sandra Pereira. (Orgs.) A síndrome do medo contemporâneo e a violência na escola. Autêntica: Belo Horizonte, 2008.

MAFESOLLI, M. Dinâmica da violência. São Paulo: Editora Da Revista dos Tribunais, 1987. 
REINHOLD, H. H. O burnout. In: LIPP, Marilda N. (Org.) O stress do professor. Campinas: Papirus, 2006. p. 63-80

TOSTA, Sandra Pereira; RIGOTTI, José Irineu Rangel et al. Rede particular de ensino em MG: vida de professor e violência na escola. Relatório de Pesquisa. Belo Horizonte: PUCMinas/ Sinpro Minas, 2009. 200p. 